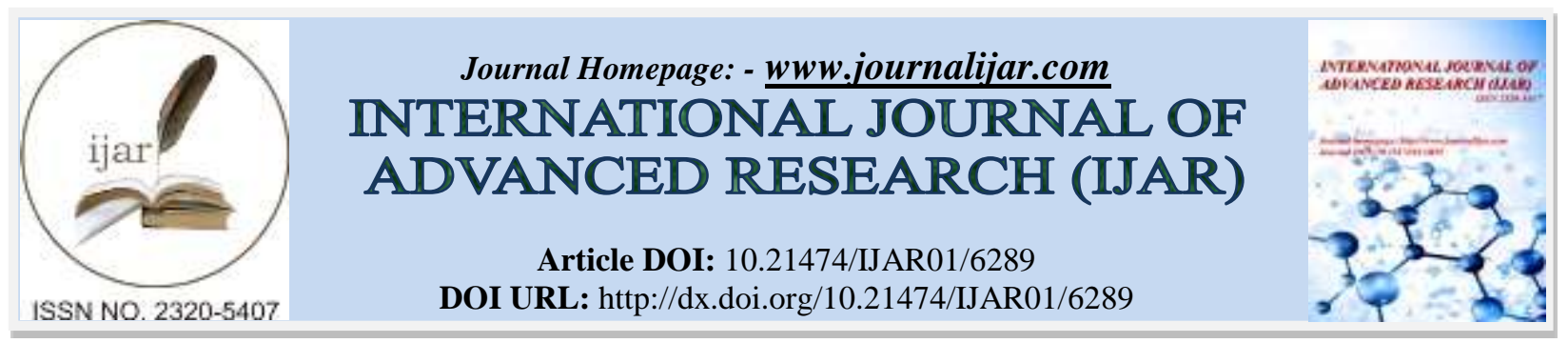

RESEARCH ARTICLE

\title{
CASE REPORT: INTESTINAL OBSTRUCTION DUE TO MIGRATORY GOSSYPIBOMA.
}

Mohammed Ali Alzayer, Ali Al- Aqoul, Abbas Alqassab and Fatimah Almabyouq. Department of General Surgery, Dammam Medical Complex, Dammam, Kingdom of Saudi Arabia.

\section{Manuscript Info}

Manuscript History

Received: 12 November 2017

Final Accepted: 14 December 2017

Published: January 2018

\section{Abstract}

A healthy 46 years old Indian male had a graham patch repair for a perforated duodenal ulcer, five months prior to his presentation with intestinal obstruction due to bowel fistulization and internal bowel migration of a retained surgical gauze. We are presenting an inadvertent but a preventable surgical complication of retained surgical items.

Copy Right, IJAR, 2018,. All rights reserved.

\section{Introduction:-}

The word Gossypiboma may have been formed from the Latin "gossypium" meaning "cotton" and "boma" meaning "place of concealment"; [1] it's also known as retained surgical sponge, gauzoma or textiloma.

Surgical sponges are the most commonly retained surgical items. This is due to their small size and that, when soked in blood, it becomes hard to distinguish them from surrounding tissues. Retained items are potentially harmful to patients due to their significant morbidity.

The aim of reporting this case is increasing awareness of both this problem, of associated risk factors, and preventing strategies among surgeons and their co-workers.

\section{Case Report:-}

History

A 46-year-old Indian gentleman underwent an open abdominal exploration, where a Graham patch repair was done for a perforated duodenal ulcer.

The patient had an uneventful postoperative course and was discharged one week after surgery.

During a follow up appointment, he was found to have a wound infection which was resolved completely after treatment with empirical antibiotics and daily dressing for one month.

Five months later, he presented himself to the emergency department complaining of "on and off" generalized abdominal pain, abdominal distension and constipation.

\section{Physical Examination:-}

The patient had mild tachycardia $103 \mathrm{bpm}$. On abdomen examination the patient had a distended abdomen with generalized tenderness, exaggerated bowel sounds and an empty rectum. 


\section{Radiological Investigation:-}

Plain abdominal radiograph was consistent with bowel obstruction and a retained gauze (Figure 1).

Computed tomography confirmed the presence of a retained gauze in the terminal ileum with the possibility of fistula formation between the jejunum and transverse colon (Figure 2).
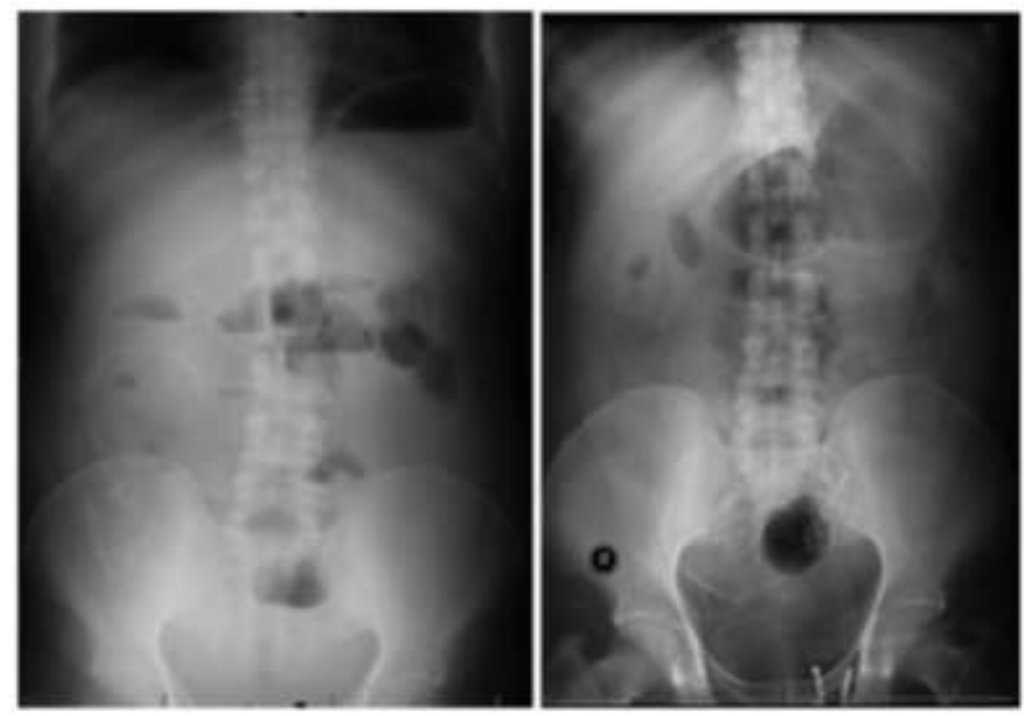

Figure 1. (A)Erect Abdomin $\mathrm{X}$-ray showing multiple air fluid level and wavy radiopaque striped lines in the right side. (B) Supine abdominal $\mathrm{X}$-ray with the gauze

\section{Management:-}

During abdominal exploration a blind entero-colic fistula between the jejunum and transverse colon was found, and it was completely sealed off by the omentum which was assumed to be the site of serosal penetration by the gauze (Figure 3). A second fistula connecting the proximal and distal jejunum was also found. The gauze was trapped in the terminal ileum proximal to the ileo-cecal junction.

Fistulectomy was done after pulling out the gauze through the distal jejunal opening, and all openings were sutured (Figure 4).

The patient had an uneventful postoperative course. 


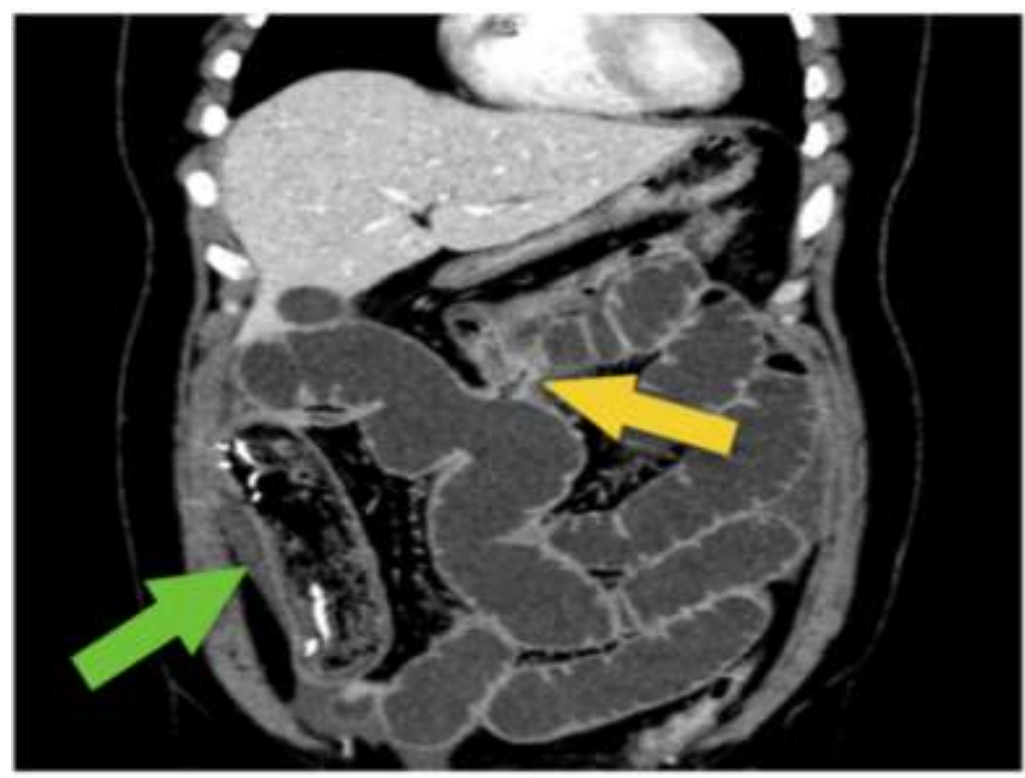

Figure 2. CT scan of the abdomen: Green arrow: Gauze in terminal ileum. Yellow arrow: Fistula between jejunum and transverse colon

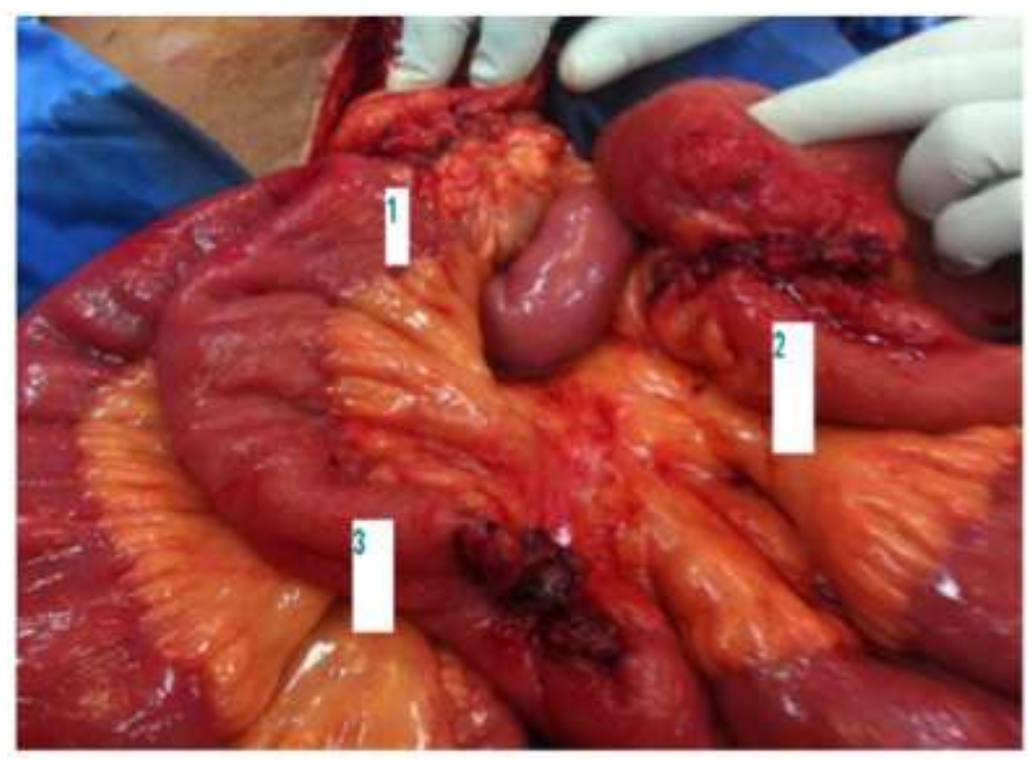

Figure 3. Intraoperative picture showing: (1)The blind entero-colic fistula (2)The proximal jejunal opening (3) The distal jejunal opening.

\section{Discussion and Conclusion:-}

Most of reported Gossypiboma cases are in patients undergoing laparotomy. [2] mostly after open cholecystectomy. [3] Gossypiboma incidences are reported in every 1000-1500 intra-abdominal operations. [4] However, due to medicolegal implications, the reporting rate is low, making it difficult to get reliable estimate of it's incidence rate. [5] 


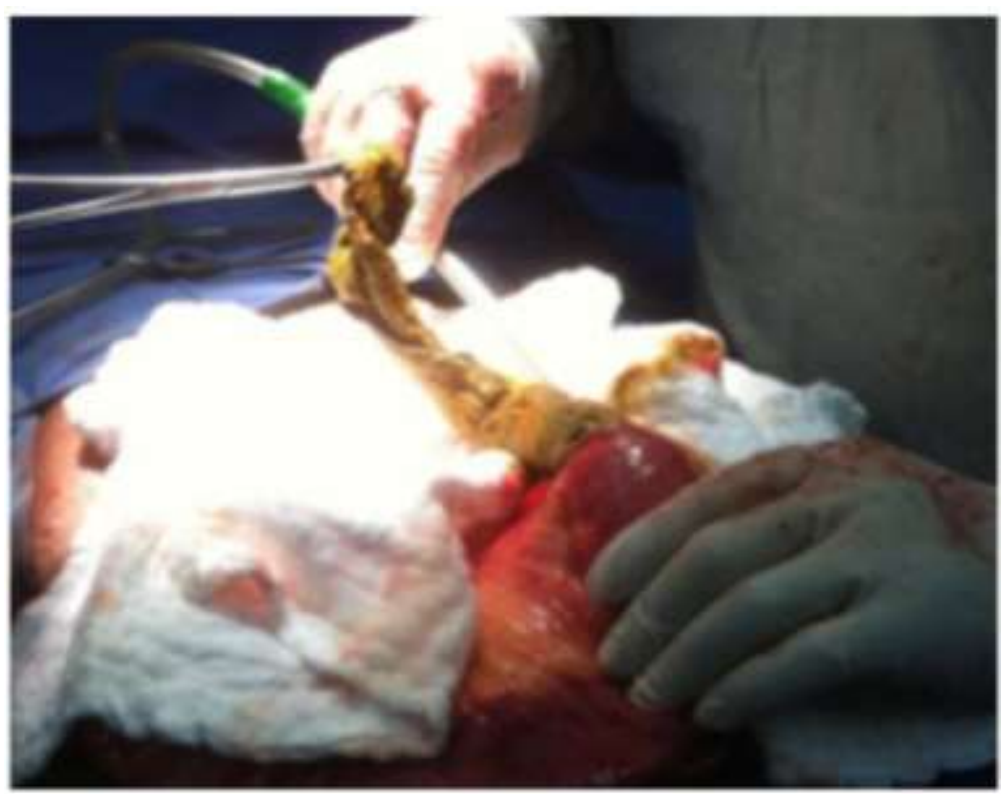

\section{Figure 4. Intraoperative picture while pulling out the retained gauze through the distal jejuna opening}

There are many risk factors that increase retention of a foreign body after surgery, such as operation performed on an emergency basis, unexpected change in operations, the involvmet of more surgical team, change in nursing staff during procedure and body-mass index. [6]

The clinical presentation of Gossypiboma can take years to manifecte after the initial surgical procedure. It varies from mild discomfort, mild or moderate pain, and malabsorption symptoms to sever pain of peritonitis or obstruction. [7] The main complications of abdominal gossypiboma are bowel perforation, obstruction, peritonitis, adhesion, abscess development, fistula formation, sepsis, and migration of the sponge into the lumens of the gastrointestinal tract. [8].

Transmural migration of a foreign body can occur in various intra-abdominal locations and is directly related to a seromuscular incision of the intestine, if made. [7] One hypothesis, proposed by Wattanasirichaigoon suggests that process of migration is divided into the followng four stages: (1) foreign body reaction, (2) secondary infection, (3) mass formation and (4) remodeling. [9] In our patient case, the mechanism of erosion and fistula formation is apparently related to the surrounding inflammatory process and local adhesion of the bowel followed by necrosis and migration of the sponge within the bowel lumen.

Once the diagnosis of gossypiboma is confirmed, endoscopic or laporscopic removal is done in order to prevent severe morbidity or mortality. [10]

Two of the most important preventive strategies are improving communication between the members of surgical team and making sure to accurately account for all foreign materials used during surgery and checking the surgical site for any foreign body at the end of the procedure. If there is any suspicion in count, an immediate intraoperative $\mathrm{X}$-rays has to be done, or if available, newer detection technologies such two-dimensional bar code, radiofrequency detector, and radiofrequency identification. [11]

In conclusion, this case report stresses the importance of maintaining a high degree of awareness and suspicion for retained surgical sponge in all postoperative patients presenting with pain, infection, or palpable masses. 


\section{References:-}

1. Rajput, P. A. Loud, J. F. Gibbs, and W. G. Kraybill, "Diag- nostic challenges in patients with tumors: case 1. Gossypiboma (foreign body) manifesting 30 years a er laparotomy," Journal of Clinical Oncology, vol. 21, no. 19, pp. 3700-3701, 2003.

2. Gumus M, Gumus H, Kapan M, Onder A, Tekbas G, Bac B. A serious medicolegal problem after surgery: gossypiboma. Am J Forensic Med Pathol 2011;33:54-7.

3. Dux M, Ganten M, Lubienski A, et al. Retained surgical sponge with migration into the duodenum and persistent duodenal fistula. Eur Radiol 2002;12(Suppl 3):S74-7.

4. E. Lincourt, A. Harrell, J. Cristiano, C. Sechrist, K. Kercher, and B. T. Heniford, "Retained foreign bodies a er surgery," Journal of Surgical Research, vol. 138, no. 2, pp. 170-174, 2007.

5. T. Uluc ay, M. G. Dizdar, M. SunayYavuz, and M. A sirdizer, " e importance of medico-legal evaluation in a case with intraabdominal gossypiboma," Forensic Science International, vol. 198, no. 1-3, pp. e15-e18, 2010.

6. Gwande AA, Studdert DM, Orav EJ, Brennan TA, Zinner MJ: Risk factors for retained instruments and sponges after surgery. N Engl J Med 2003, 348(3):229-235.

7. Unconsidered cause of bowel obstruction -gossypiboma, Deborshi Sharma et al, J can chir, Vol. 51, No 2, april 2008

8. Lv et al.: Intractable duodenal ulcer caused by transmural migration of gossypiboma into the duodenum - a case report and literature review. BMC Surgery 2014 14:36.

9. Wattanasirichaigoon S. Transmural migra- tion of a retained surgical sponge into the intestinal lumen: an experimental study.

10. J Med Assoc Thai 1996;79:415-22.

11. H.-S. Sun, S.-L. Chen, C.-C. Kuo, S.-C. Wang, and Y.-L. Kao, "Gossypiboma-retained surgical sponge," Journal of the Chinese Medical Association, vol. 70, no. 11, pp. 511-513, 2007.

12. Rabi Sankar Biswas,Suvro Ganguly et all, Gossypiboma and Surgeon- Current Medicolegal Aspect - A Review, Indian J Surg (July-August 2012) 74(4):318-322 